\title{
Prenatal listening to songs composed for pregnancy and symptoms of anxiety and depression: a pilot study
}

\author{
Chineze Nwebube ${ }^{1}$, Vivette Glover ${ }^{2}$ and Lauren Stewart ${ }^{1,3^{*}}$
}

\begin{abstract}
Background: Prenatal anxiety and depression are distressing for the expectant mother and can have adverse effects on her fetus and subsequently, her child. This study aimed to determine whether listening to specially composed songs would be an effective intervention for reducing symptoms of prenatal anxiety and depression.

Methods: Pregnant women were recruited online and randomly assigned to one of two groups: the music group (daily listening to specially composed songs) or control group (daily relaxation) for 12 weeks each. Self-report questionnaires were used to assess symptoms of State and Trait anxiety (Spielberger) and depression (Edinburgh Postnatal Depression Scale (EPDS)). Trait anxiety was measured as the primary outcome, while State anxiety and depression were the secondary outcomes. 111 participants were randomised to each group. 20 participants in the intervention group and 16 participants in the active control group completed the study.

Results: The music group demonstrated lower Trait Anxiety ( $p=.0001)$ (effect size 0.80), State Anxiety $(p=.02)$ (effect size 0.64), and EPDS ( $p=.002$ ) (effect size 0.92) scores at week 12 compared to baseline, by paired t test. There were no such changes in the control group.

Conclusions: Though this pilot study had high levels of attrition, the results do suggest that regular listening to relaxing music should be explored further as an effective non-pharmacological means for reducing prenatal anxiety and depression.
\end{abstract}

Trial registration: ClinicalTrials.gov NCT02776293 LV-001. Registered 17 May 2016. Retrospectively registered.

Keywords: Prenatal, Anxiety, Depression, Music

\section{Background}

There is good evidence that if a mother is anxious, depressed or stressed while she is pregnant, this is not only distressing for the mother, but it can also cause problems for her future child [1]. The child is at increased risk for anxiety and depression, behavioural problems such as Attention Deficit Hyperactivity Disorder (ADHD) and conduct disorder, as well as sub-optimal cognitive development [2]. There is also an increased risk of physical problems such as asthma and altered immune function

\footnotetext{
* Correspondence: I.stewart@gold.ac.uk

'Department of Psychology, Goldsmiths, University of London, 8 Lewisham Way, London SE14 6NW, UK

${ }^{3}$ Centre for Music in the Brain, Department of Clinical Medicine, Aarhus University \& The Royal Academy of Music Aarhus/Aalborg, Nørrebrogade 44, 8000 Aarhus C, Denmark

Full list of author information is available at the end of the article
}

$[3,4]$. All this appears to be, at least in part, due to fetal programming. The mother is also more likely to suffer from postnatal depression if she is anxious or depressed while pregnant and her baby is likely to be premature and smaller for gestational age [5]. These consequences can occur with mild to moderate symptoms of anxiety and depression, not only with severe stress or a clinically diagnosed mental illness [6]. It is therefore very important both to detect and to help ameliorate symptoms of anxiety and depression in pregnant women [7]. Many women do not want pharmacological interventions at this time, and with less severe symptoms it may not be appropriate. Thus there is a need to find non-pharmacological methods of intervention. Psychological therapies such as cognitive behavioural therapy or interpersonal therapy 
can be effective but these are often not available for the large numbers of women who could benefit.

There is a large body of research showing that listening to music can alter mood and arousal [8]. In terms of clinical applications, it can, for instance, lessen anxiety before dentistry [9] and reduce anxiety and depression in older adults [10]. A study with pregnant women who listened to music prior to amniocentesis showed that it reduced both state anxiety and cortisol levels [11], while an intervention that involved pregnant women learning to sing lullabies during pregnancy was found to aid emotional expression, reduce the amount of self-reported anxiety and contribute to a positive experience during pregnancy [12]. Interestingly, animal studies have shown that exposure to music during pregnancy can benefit brain development in the offspring. Chikahisa et al. [13] showed that if mice were played Mozart in the perinatal period it enhanced the learning performance and altered the brain Brain Derived Neurotrophic Factor/ Tropomyosin Kinase B (BDNF/TrkB) signaling in the adult offspring. Sheikhi and Saboory [14] have shown that exposure of pregnant rats to classical music throughout pregnancy resulted in the offspring having significantly higher cell density in the parietal cortex while Kim et al. [15] have shown that exposure to music during pregnancy increased neurogenesis in the motor and somatosensory cortex of the rat pups.

In this small pilot study we explored the possibility that listening to original songs specially composed for the prenatal period may reduce symptoms of anxiety and depression in pregnant women over a period of 12 weeks. We used a control condition of sitting quietly and undisturbed, which has been shown in an acute study to reduce anxiety and cortisol levels [16]. Proof of efficacy would justify investment into music as an accessible, inexpensive and non-stigmatizing method with potential to improve the mother's mental health and benefit both the mother and child.

\section{Methods}

The study was conducted between March 2014 and August 2015. The Ethics committee at Goldsmiths, University of London, approved this study. Informed consent was obtained online, prior to the start of the questionnaires.

\section{Participants}

The women were recruited online via a specially designed website, The Relaxation in Pregnancy Study. The study was publicized on various websites, such as Netmums, and also by leaflets that were distributed in hospitals, ultrasound clinics, baby and toddler groups and coffee shops throughout London, UK. Pregnant women over 18 years from English speaking countries were eligible. Participants were randomized through a blocked design of random sizes using research randomizer. A research associate not involved in the study conducted the randomization. Individual group assignments were placed in opaque sealed envelopes to ensure allocation concealment.

Two hundred twenty-two participants completed the questionnaires on entry into the study and were randomly allocated to the control or music group (control group 111; music group 111). Their characteristics are shown in Table 1. There were no significant differences between these two groups. Thirty-six of these (control

Table 1 Baseline Characteristics of participants in control $(n=111)$ and music groups $(n=111)$

\begin{tabular}{llll}
\hline & Total & Control & Music Group \\
\hline Country, N (\%) & & & \\
Australia, & $1(0.46 \%)$ & $1(100 \%)$ & 0 \\
Canada & $23(10.60 \%)$ & $8(35 \%)$ & $15(65 \%)$ \\
China & $1(0.46 \%)$ & 0 & $1(100 \%)$ \\
India & $1(0.46 \%)$ & 0 & $1(100 \%)$ \\
Malaysia & $1(0.46 \%)$ & 0 & $1(100 \%)$ \\
Philippines & $1(0.46 \%)$ & 0 & $1(100 \%)$ \\
Romania & $1(0.46 \%)$ & $1(100 \%)$ & 0 \\
United Kingdom & $187(86 \%)$ & $96(51 \%)$ & $91(49 \%)$ \\
$\quad$ United States & $1(0.46 \%)$ & 0 & $1(100 \%)$ \\
Gestational Age & 15.84 & $15.37(8.74)$ & $16.29(8.88)$
\end{tabular}

Age Finished Full Time Education, N (\%)

\begin{tabular}{llll} 
Over 25 & $30(18 \%)$ & $13(43 \%)$ & $17(57 \%)$ \\
Under 25 & $59(36 \%)$ & $32(54 \%)$ & $27(46 \%)$ \\
Under 22 & $71(43 \%)$ & $32(45 \%)$ & $39(55 \%)$ \\
Under 16 & $4(3 \%)$ & $1(25 \%)$ & $3(75 \%)$ \\
Method of Recruitment, N (\%) & & & \\
Conference & $2(1.8 \%)$ & $1(50 \%)$ & $1(50 \%)$ \\
Family Member & $1(0.9 \%)$ & 0 & $1(100 \%)$ \\
Flyer & $1(0.9 \%)$ & $1(100 \%)$ & 0 \\
Friend & $5(4.6 \%)$ & $2(40 \%)$ & $3(60 \%)$ \\
Website & $14(12.8 \%)$ & $7(50 \%)$ & $7(50 \%)$ \\
Mother \& Baby & $1(0.9 \%)$ & $1(100 \%)$ & 0 \\
Mumsnet & $8(7.3 \%)$ & $3(37.5 \%)$ & $5(62.5 \%)$ \\
NCT & $2(1.8 \%)$ & $2(100 \%)$ & 0 \\
Netmums & $60(55 \%)$ & $31(52 \%)$ & $29(48 \%)$ \\
Physician & $2(1.8 \%)$ & $1(50 \%)$ & $1(50 \%)$ \\
Recruiter & $4(1.8 \%)$ & 0 & $4(100 \%)$ \\
Social Media & $9(8.3 \%)$ & $4(44 \%)$ & $5(56 \%)$ \\
Psychometric Characteristics & & & $3.73(5.36)$ \\
Trait Anxiety (Spielberger) & $41.02(12.28)$ & $42.39(11.13)$ & $39.75(13.26)$ \\
State Anxiety (Spielberger) & $39.15(13.46)$ & $40.15(13.15)$ & $38.23(13.83)$ \\
Depression (EPDS) & $8.75(6.14)$ & $9.85(6.77)$ & $7.7 \%$ \\
\hline
\end{tabular}


group 16; music group 20) also completed the questionnaires at 12 weeks. The attrition rate was comparable across both groups. Figure 1 illustrates the number of participants per group at each stage of the study.

Sample size estimations have been made to power the study using $\mathrm{G}^{*}$ Power 3.1. An effect size of 0.57 was estimated based on effect sizes of studies involving forms of relaxation on Trait Anxiety [17]. Assuming an effect size of 0.57, and a two-tailed alpha of 0.05 , a sample of 50 participants per group was deemed necessary to generate a power of 0.80 .

Both the control and music groups were asked to listen to their assigned audio file for at least $20 \mathrm{~min}$ a day and to record each time they had engaged in this activity. Twelve weeks after each participant had started the study they were prompted to complete the EPDS, and StateTrait Anxiety Index for a second time. Participants were sent follow- up emails every 2 weeks that served as a reminder for the participants to listen to their assigned mp3 files. At the end of 12 weeks, participants were prompted to complete the questionnaire. Participants who had not completed their questionnaire by the deadline were prompted to complete the questionnaire every 5 days past the deadline for a maximum of 3 times.

\section{Materials}

Qualtrics software was used to administer the questionnaires and participants were prompted to complete these via email at the respective time points. Participants received an audio file specific to the assigned group electronically. Both audio files began with a $2 \mathrm{~min}$ introduction given via the same speaker; following this, participants were instructed to either sit quietly and undisturbed (control group) or to listen to prerecorded songs (music group), for $20 \mathrm{~min}$. Composer Jennie Muskett wrote these songs specifically for use during pregnancy. The songs were composed using specific tempos, musical shapes and phrases aimed at inducing a calm state. The music was original and therefore had no previous associations. Use of some of the musical characteristics typical of traditional lullabies, incremental reductions in tempo, and repetition of musical phrases, many of which were derived from motherese, all aimed to further enhance the effect. The song lyrics invited connection with, and visualisation of the fetus and each song addressed various issues relevant to pregnant women. The instrumentation and timbre was intimate, performed vocally and accompanied entirely by acoustic instruments.

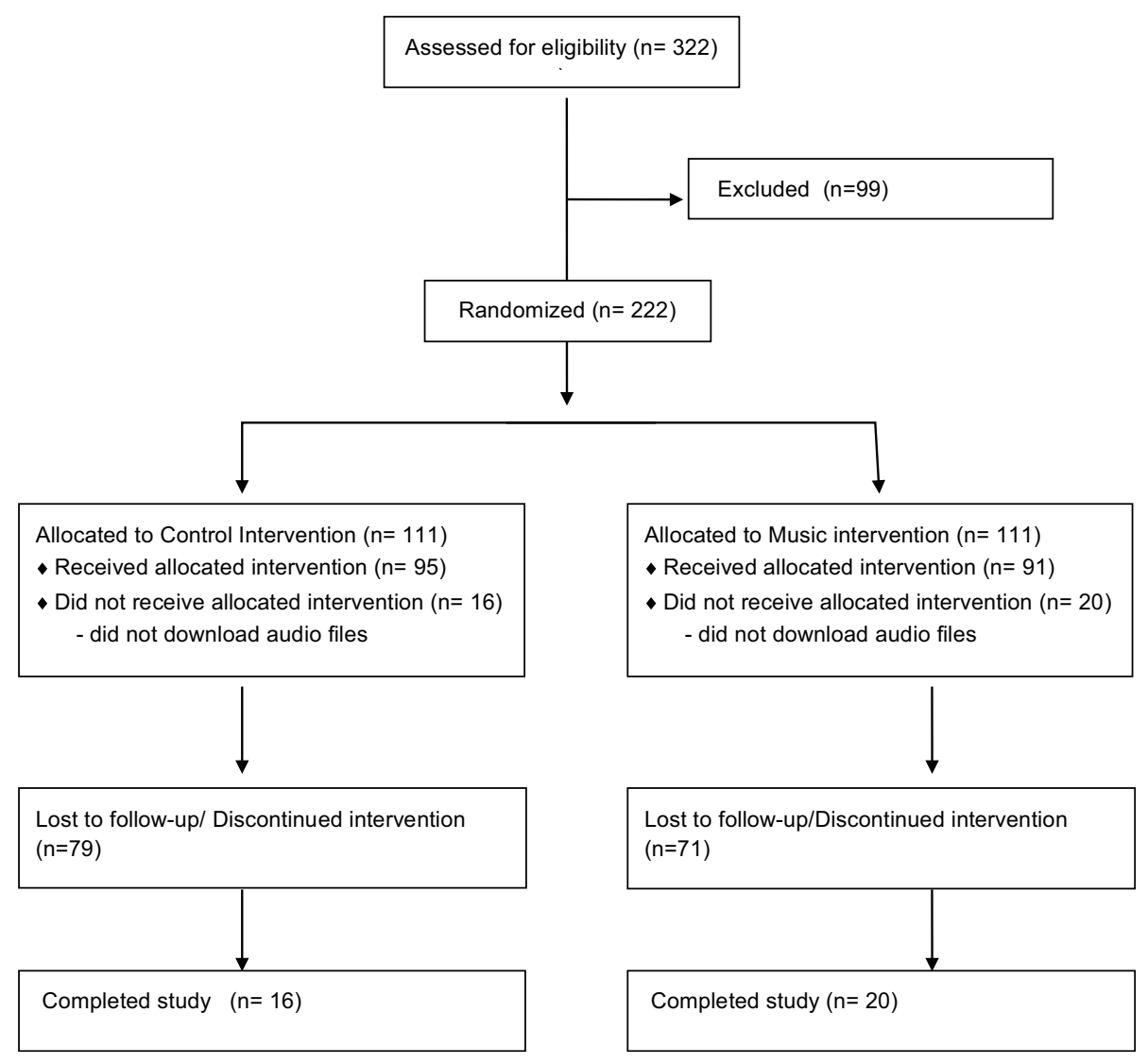

Fig. 1 Flow diagram of participant progress through the phases of the study 
Table 2 Anxiety and depression scores at baseline and 12 weeks in the control $(n=16)$ and music groups $(n=20)$ who completed the study

\begin{tabular}{|c|c|c|c|c|c|c|}
\hline & Control baseline & Control 12 weeks & $p$ & Music baseline & Music 12 weeks & $p$ \\
\hline $\begin{array}{l}\text { Spielberger } \\
\text { Trait }\end{array}$ & $42.8 \pm 8.0$ & $38.8 \pm 12.5$ & 0.155 & $38.5 \pm 10.9$ & $30.6 \pm 8.6$ & 0.001 \\
\hline $\begin{array}{l}\text { Spielberger } \\
\text { State }\end{array}$ & $38.9 \pm 12.0$ & $35.2 \pm 14.3$ & 0.138 & $37.1 \pm 12.1$ & $30.3 \pm 8.9$ & 0.02 \\
\hline EPDS & $9.3 \pm 5.1$ & $7.3 \pm 6.0$ & 0.095 & $8.5 \pm 5.3$ & $4.0 \pm 4.4$ & 0.002 \\
\hline
\end{tabular}

Comparison in Scores by paired t-test. $P$ value tests for significant differences between the two time points

\section{Self-report questionnaires}

Symptoms of Trait anxiety, the primary outcome, and symptoms of State Anxiety and Depression, the secondary outcomes, were assessed using self-report questionnaires.

\section{Edinburgh postnatal depression scale}

The Edinburgh Postnatal Depression Scale [(EPDS), validated for prenatal use] is a 10 item questionnaire measuring symptoms of maternal depression. This scale is scored from 0 to a maximum of 30 , with a higher number representing a more depressed state [18].

\section{State - trait anxiety inventory}

The State - Trait Anxiety Inventory is a questionnaire widely used for measuring maternal anxiety [19]. The index is divided into state and trait, each composed of 20 items on a 4 point likert scale. Answer choices range from 1 (not at all) to 4 (very much so). The questionnaire is scored from 20 to a maximum of 80 with a higher number representing a more anxious state. The Spielberger State Index measures the anxiety of an individual at the time of taking the questionnaire whereas the Spielberger Trait Index measures an individual's general level of anxiety.

\section{Results}

There were no significant differences in baseline gestational age in weeks (mean \pm SD) at baseline $(13.7 \pm 9.0$ versus $18.2 \pm 7.7$ ) or days spent relaxing or listening $(38.8 \pm 21$ versus $44.3 \pm 23.7)$ between the control $(n=16)$ and music group $(n=20)$ respectively, who completed the study.

Table 2 shows the baseline and 12-week scores for symptoms of anxiety (Trait and State) and symptoms of depression (EPDS). Paired t-tests demonstrated significantly lower scores in the music group at week 12 compared to baseline in all 3 measures. The effect sizes for Trait anxiety, State anxiety, and Depression were 0.80 , 0.64 , and 0.92 , respectively. In the control group, no significant differences were found [See Additional file 1 for complete dataset].

\section{Discussion}

The results of this small study look promising, in that over the 12-week period, participants' symptoms of anxiety and depression decreased significantly in the music group and did not change significantly in the control group. It is of note that the baseline scores in both groups are above average [19]; it appears that women with somewhat raised symptoms of anxiety and depression chose to take part in the study.

There are several obvious limitations to this study. The first is the high attrition rate. This may well be because the investigators had no direct contact with the participants, as all recruitment and follow up was online. It may also be that only some women find listening to music helpful or enjoyable; but an intervention that benefits a subgroup could still be of great value. Though only the music group showed significant reduction in anxiety and depression, the interaction between group and time was not statistically significant using a Mixed Analysis of Variance (ANOVA). This is likely due to the small numbers, and emphasizes the need for a larger study, with personal contact and better retention. We also do not know if other music would be equally effective. The songs used here were specifically composed and designed to have a calming effect.

Despite these limitations, the magnitude of reduction of the scores in the music listening group is notable, from a mean of 38.5 to 30.6 for Trait anxiety and from a mean of 8.4 to 3.75 for the EPDS. We know that the means of the scores for these questionnaires generally tend to remain quite stable over pregnancy [20], and reductions of this magnitude could be clinically significant.

\section{Conclusions}

These results do suggest that further research in this area is warranted. Listening to music during pregnancy is a potentially enjoyable, inexpensive and non-stigmatizing intervention that may also be beneficial for the future child.

\section{Additional file}

Additional file 1: Dataset: EPDS, State Anxiety and Trait Anxiety Scores at Baseline and 12 weeks in the control and music groups. 


\section{Abbreviations}

ADHD: Attention deficit hyperactivity disorder; ANOVA: Analysis of variance; BDNF: Brain derived neurotrophic factor; EPDS: Edinburgh Postnatal Depression Scale; TrkB: Tropomyosin receptor kinase B

\section{Acknowledgements}

We would like to thank Laura Freeman for creating the website, as well as Annalise Pask, Karen Sonego and Netmums for their tremendous help with promoting the study, significantly helping recruitment. Center for Music in the Brain (LS) is funded by the Danish National Research Foundation (DNRF117).

\section{Availability of data and materials}

The dataset supporting the conclusions of this article is included in Additional file 1 .

\section{Authors' contributions}

VG and LS conceived the study. CN was responsible for data collection and study coordination. All authors contributed to the drafting of the manuscript. All authors read and approved the final manuscript.

\section{Competing interests}

The authors declare that they have no competing interests.

\section{Consent for publication}

Not applicable.

\section{Ethics approval and consent to participate}

The Ethics committee at Goldsmiths, University of London, approved this study. Informed consent was obtained online, prior to the start of the questionnaires.

\section{Publisher's Note}

Springer Nature remains neutral with regard to jurisdictional claims in published maps and institutional affiliations.

\section{Author details}

'Department of Psychology, Goldsmiths, University of London, 8 Lewisham Way, London SE14 6NW, UK. ${ }^{2}$ Institute of Reproductive and Developmental Biology, Imperial College London, Hammersmith Campus, Du Cane Road, London W12 ONN, UK. ${ }^{3}$ Centre for Music in the Brain, Department of Clinical Medicine, Aarhus University \& The Royal Academy of Music Aarhus/Aalborg, Nørrebrogade 44, 8000 Aarhus C, Denmark.

\section{Received: 30 October 2016 Accepted: 27 April 2017}

\section{Published online: 08 May 2017}

\section{References}

1. Talge NM, Neal C, Glover V. Antenatal maternal stress and long-term effects on child neurodevelopment: how and why? J Child Psychol Psychiatry. 2007:48(3-4):245-61.

2. O'Connor TG, Heron J, Golding J, Beveridge M, Glover V. Maternal Antenatal anxiety and Children's Behavioural/emotional problems at 4 years: report from the Avon longitudinal study of parents and children. Br J Psychiatry. 2002;180:502-8

3. Cookson H, Granell H, Joinson C, Ben-Shlomo Y, Henderson AJ. Mothers' anxiety during pregnancy is associated with asthma in their children. J Allergy Clin Immunol. 2009;123(4):847-53.

4. O'Connor TG, Winter MA, Hunn J, Carnahan J, Pressman EK, Glover V, Robertson-Blackmore E, Moynihan JA, Eun-Hyung Lee F, Caserta MT. Prenatal maternal anxiety predicts reduced adaptive immunity in infants. Brain Behav Immun. 2013;32:21-8.

5. Lee AM, Lam Sze ML, Chong CS, Chui HW, Fong DY. Prevalence, course, and risk factors for Antenatal anxiety and depression. Obstet Gynecol. 2007; 110(5):1102-12

6. O'Donnell KJ, Glover V, Barker ED, O'Connor TG. The persisting effect of maternal mood in pregnancy on childhood psychopathology. Dev Psychopathol. 2014;26(2):393-403.

7. Glover V. Maternal depression, anxiety and stress during pregnancy and child outcome; what needs to be done. Best Pract Res Clin Obst Gynaecol. 2014; $28(1): 25-35$

8. Juslin PN, Sloboda JA. Music and emotion: Theory and research. Oxford: Oxford University Press; 2001.
9. Thoma MV, Zemp M, Kreienbühl L, Hofer D, Schmidlin PR, Attin T, Ehlert U, Nater UM. Effects of music listening on pre-treatment anxiety and stress levels in a dental hygiene recall population. Int J Behav Med. 2015;22(4):498-505.

10. Klainin-Yobas P, Oo WN, Suzanne Yew PY, Lau Y. Effects of relaxation interventions on depression and anxiety among older adults: a systematic review. Aging Ment Health. 2015;19(12):1043-5.

11. Ventura T, Gomes MC, Carreira T. Cortisol and anxiety response to a relaxing intervention on pregnant women awaiting amniocentesis. Psychoneuroendocrinology. 2012;37:148-56.

12. Carolan M, Barry M, Gamble M, Turner K, Mascareñas O. The limerick lullaby project: an intervention to relieve prenatal stress. Midwifery. 2012;28:173-80.

13. Chikahisa S, Sei H, Morishima M, Sano A, Kitaoka K, Nakaya Y, Morita Y. Exposure to music in the perinatal period enhances learning performance and alters BDNF/TrkB signaling in mice as adults. Behav Brain Res. 2006; 169(2):312-9.

14. Sheiki S, Saboory E. Neuroplasticity changes of rat brain by musical stimuli during fetal period. Cell J. 2015;16(4):448-55.

15. Kim CH, Lee SC, Shin JW, Chung KJ, Lee SH, Shin MS, Baek SB, Sung YH, Kim CJ, Kim KH. Exposure to music and noise during pregnancy influences neurogenesis and thickness in motor and somatosensory cortex of rat pups. Int Neurourol J. 2013;17(3):107-13.

16. Teixeira J, Martin D, Prendiville $\mathrm{O}$, Glover $\mathrm{V}$. The effects of acute relaxation on indices of anxiety during pregnancy. J Psychosom Obstet Gynaecol. 2005;26(4):271-6.

17. Manzoni GM, Pagnini F, Castelnuovo G, Molinari E. Relaxation training for anxiety: a ten-years systematic review with meta-analysis. BMC Psychiatry. 2008;8(1):41

18. Murray D, Cox JL. Screening for depression during pregnancy with the Edinburgh depression scale (EPDS). J Reprod Infant Psychol. 1990;8:99-107.

19. Spielberger CD, Gorsuch RL, Lushene R, Vagg PR, Jacobs GA. Manual for the state-trait anxiety inventory. Palo Alto: Consulting Psychologists Press; 1983.

20. Sarkar P, Bergman K, Fisk NM, Glover V. Maternal anxiety at amniocentesis and plasma cortisol. Prenatal Diag. 2006:26:505-9.

\section{Submit your next manuscript to BioMed Central and we will help you at every step:}

- We accept pre-submission inquiries

- Our selector tool helps you to find the most relevant journal

- We provide round the clock customer support

- Convenient online submission

- Thorough peer review

- Inclusion in PubMed and all major indexing services

- Maximum visibility for your research

Submit your manuscript at www.biomedcentral.com/submit
Biomed Central 